\title{
EFFECT OF ANODE DEPTH IN SYNTHESIS OF BIODIESEL USING THE ANODIC PLASMA ELECTROLYSIS METHOD
}

\author{
Nelson Saksono ${ }^{1 *}$, Ratih Anditashafardiani ${ }^{1}$, Adream Bais Junior ${ }^{1}$, Yuswan Muharam ${ }^{1}$ \\ ${ }^{1}$ Department of Chemical Engineering, University of Indonesia, Kampus Baru UI Depok, West Java, \\ 16424, Indonesia
}

(Received: July 2018 / Revised: October 2018 / Accepted: April 2019)

\begin{abstract}
Plasma electrolysis is a process of electrolysis that uses a DC current to excite electrons in the electrolyzed solution. The method is very prolific in producing hydroxyl radical $(\mathrm{OH} \bullet)$, which is then used to react with methanol and form a methoxyl radical $\left(\mathrm{CH}_{3} \mathrm{O} \cdot\right)$. Methoxyl radical is used to break the bond of triglycerides to form methyl ester (biodiesel) and glycerol. The purpose of this study is to obtain a good quality and quantity of biodiesel by examining the effect of anode depth with a constant contact area where the anode is the spot of plasma formed. The solution used contains Refined, Bleached, and Deodorized Palm Oil and methanol with a molar ratio of $1: 24$ and a concentration of $\mathrm{KOH} 1 \%$-wt. The variations of anode depth are $0.5 \mathrm{~cm}, 1.5 \mathrm{~cm}$, and $3.5 \mathrm{~cm}$ below the surface of the solution, with $5 \mathrm{~mm}$ as the constant contact area. The results of this research show an improvement in efficiency, as indicated by yield, and the energy consumption of biodiesel synthesis with increasing depth of the anode. The maximum yield was reached at an anode depth of $3.5 \mathrm{~cm}$, which produced $96.09 \%$ as a biodiesel yield with $0.039 \%$ vol water content, 0.138 as the acid number, and a specific energy requirement of $0.909 \mathrm{~kJ} / \mathrm{ml}$.
\end{abstract}

Keywords: Anode depth; Anodic plasma; Biodiesel; Plasma electrolysis

\section{INTRODUCTION}

The application of plasma electrolysis has proven to be effective in the production of valuable products, such as hydrogen, with a low consumption of energy (Saksono et al., 2016). The method has also been proven to degrade complex organic waste, such as phenol (Saksono et al., 2015). The application of the technology to biodiesel production is an interesting topic to explore due to the fact that biodiesel is attracting global attraction as an alternative fuel type owing to its biodegradability and environmental friendliness (Haron et al., 2017). The synthesis of biodiesel using the plasma electrolysis method offers a breakthrough because it can accelerate the rate of synthesis and reduce specific energy consumption, compared to the conventional methods (Saksono et al., 2018).

Conventional biodiesel synthesis using Crude Palm Oil (CPO) generally employs the transesterification, or alcoholysis, reaction method of triglycerides using a homogeneous catalyst in the form of an acid catalyst $\left(\mathrm{H}_{2} \mathrm{SO}_{4}, \mathrm{HCl}\right)$ and alkaline $(\mathrm{NaOH}, \mathrm{KOH})$. It is most common for alkaline catalysts to be used in the production process of biodiesel plants due to the speed and ease of the process. However, the process also has the disadvantage of forming significant volumes of water and soap from a sapling reaction, which results in a decrease in the quality of the catalyst used. In addition, the method is characterized by its slow reaction rate and a tendency

\footnotetext{
${ }^{*}$ Corresponding author's email: nelsonsaksono@gmail.com, Tel. +62-852-18464708, Fax. +62-21-7863515
} Permalink/DOI: https://dx.doi.org/10.14716/ijtech.v10i3.2919 
for the reaction to sometimes stop prior to $100 \%$ conversion into a product in the form of biodiesel (Boocock et al., 1998). It is possible to overcome this weakness by using an acid catalyst. However, while acid catalysts can negate the saponification reaction, they also require complex and corrosive conditions, which also require a long separation time. In addition, the acid and base catalysts need to be processed first, thereby entailing additional costs.

Plasma, on the other hand, produces a large amount of methoxyl radical $\left(\mathrm{CH}_{3} \mathrm{O} \bullet\right.$ ) (Zong et al., 2009) that will react with triglycerides to form biodiesel. Plasma can be either cathodic or anodic, depending on the electrode where the plasma is formed. In general, plasma is more stable and easily formed in the cathode than the anode because the cathode emits more secondary electrons (Bruggeman \& Leys, 2009). Plasma electrolysis is a process of electrolysis that uses a DC current to form electric sparks as a result of the electrons undergoing plasma excitation in the electrolyzed solution (Saito et al., 2015).

Initially, methanol is mixed with potassium hydroxide to produce the species shown in Equation 1 (Lotero et al., 2005). In the plasma electrode, the high-energy electrons produced by the plasma will break apart water molecule into radicals and transform methoxyl ions into methoxyl radicals (Zong et al., 2009). Meanwhile, on the other electrode, where there is no plasma, a conventional electrolysis reaction will take place that produces ions (Kozáková, 2011). Using anodic plasma, the reactions denoted in Equations 2 and 3 occur in the anode, while the reaction in Equation 4 takes place in the cathode.

$$
\begin{aligned}
& \mathrm{CH}_{3} \mathrm{OH}_{(a q)}+\mathrm{KOH}_{(a q)} \rightarrow \mathrm{CH}_{3} \mathrm{O}^{-}{ }_{(a q)}+\mathrm{K}^{+}{ }_{(a q)}+\mathrm{H}_{2} \mathrm{O}_{(l)} \\
& \mathrm{H}_{2} \mathrm{O}_{(l)}+e^{*} \rightarrow \mathrm{H} \cdot+\mathrm{OH} \cdot+e^{-} \\
& \mathrm{CH}_{3} \mathrm{O}^{-}{ }_{(a q)}+e^{*} \rightarrow \mathrm{CH}_{3} \mathrm{O} \cdot+e^{-} \\
& 2 \mathrm{H}_{2} \mathrm{O}_{(l)}+2 e^{-} \rightarrow 2 \mathrm{OH}^{-}+\mathrm{H}_{2}(g)
\end{aligned}
$$

The methoxyl radicals produced by those reactions will attack the triglycerides in palm oil and produce methyl esters (Lotero et al., 2005). In general, the mechanism consists of three stages as shown in Figure 1 (Lee et al., 2009). The first stage is a nucleophilic alkoxide attack producing a tetrahedral intermediate. The second stage is the formation of alkyl ester and anion diglyceride. The third stage is the regeneration of the active species that will react with the second molecule of the other alcohol, followed by the recovery of the base catalyst.<smiles>[R]OC(=O)OCC(COC([R])=O)C([R])=O</smiles><smiles>[R]OC([R])=O</smiles><smiles></smiles><smiles>[R]OC(=O)OCC(C[18O])C([R])OC([R])=O</smiles><smiles>[R]OC([R])=O</smiles><smiles>[R]C(=O)OCC(CO)OC([R])=O</smiles>

$$
\mathrm{OH}^{-}+\mathrm{K}^{+} \rightleftharpoons \mathrm{KOH}
$$

Figure 1 Hypothesis of reaction mechanisms (Lee et al., 2009) 
In previous research (Saksono et al., 2018), the synthesis of biodiesel using plasma electrolysis has been proven to produce biodiesel products. This research aims to increase the effectivity of the plasma electrolysis method to produce biodiesel. The main objective of this study was to observe the effect of the depth of the anode (which is partially coated by quartz glass) in the solution, where the plasma formation takes place in the anode. The contact area between the anode and solution will remain constant, even when the anode depth is increased; this is done by using a quartz glass coating, which will be explained further in the next section. The effect of anodic plasma depth with a constant anode contact area is crucial because a deeper anode position will affect the amount of energy consumed (Bismo et al., 2013).

\section{METHODS}

\subsection{Materials}

The palm oil used was a commercial cooking oil produced in Indonesia. Methanol (analytical grade) and potassium hydroxide were used as the transesterification agent and catalyst, respectively. Water was used for cooling. Specifically, the palm oil used was Refined, Bleached, and Deodorized Palm Oil (RBDPO), $\mathrm{KOH} 1 \%-\mathrm{wt}$ RBDPO with a molar ratio of RBDPO:methanol = 1:24.

\subsection{Instrumentation}

The main equipment used was a Single Anode Contact Glow Discharge Electrolysis (CGDE) reactor, which was adapted from previous research by Gao et al. (2003), as shown in Figure 2. The reactor comprised a cylindrical glass tube with an inner diameter of $83 \mathrm{~mm}$ and a height of $122 \mathrm{~mm}$, which was operated in a batch system, while the cooling water was circulated around the reactor. The tungsten electrode acted as the plasma-generated electrode, which was $1.6 \mathrm{~mm}$ in diameter. The difference lay in the type of charge delivered to the tungsten as the electrode where the plasma is formed. When tungsten is given a negative charge, it acts as a cathode. Conversely, when a positive charge is given, it will act as an anode. In this research, the tungsten, as the electrode where the plasma will be formed, will act as an anode. The cathode was made of stainless steel with a diameter of $5 \mathrm{~mm}$ and partially placed in an immersed condition at a depth of $30 \mathrm{~mm}$, within the solution of the system. The distance between the anode and the cathode was $40 \mathrm{~mm}$. Stainless steel SS 316 has a larger surface area in contact with the solution, thus ensuring no plasma is formed in the cathode. Stirring was performed using a magnetic stirrer with the addition of a baffle inside the reactor, with the latter used to make the stirring more effective. The reactor was equipped with a coolant stream to maintain the temperature inside the reactor at 50 $60^{\circ} \mathrm{C}$ in order to reduce the possibility of methanol evaporating from the solution. The reactor is a batch type with an added baffle and cooling jacket to maintain the temperature at $50-60^{\circ} \mathrm{C}$ (Devitria \& Anita, 2013).

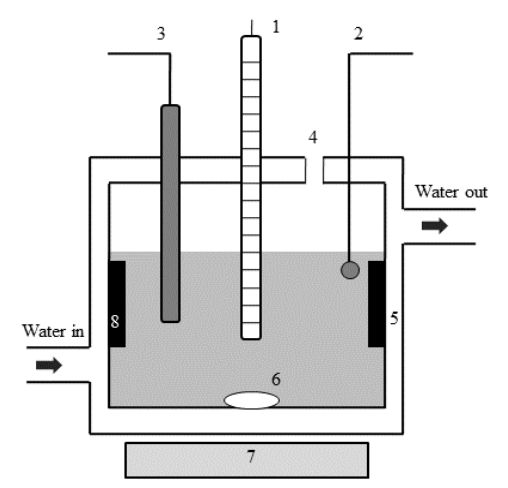

Note:

1. Thermometer 5. Cooling jacket

2. Cathode, SS $316 \quad$ 6. Magnetic bar

3. Anode, Tungsten 7. Magnetic stirrer

4. Hole Baffle

Figure 2 Single anode contact glow discharge electrolysis reactor 
The other equipment used in this research comprised a transformer, slide regulator, diode, multimeter, thermometer, cables, and a mini circuit breaker. Figure 3 shows the series of equipment that was used in this research. It was necessary to implement this series of equipment in the Single Anode CGDE reactor for several reasons. The type of current that can be used in plasma electrolysis processing is a direct current (DC), not an alternating current (AC); therefore, the diode bridge will function as the modifier from AC to DC. A transformer is also necessary to step up the voltage since plasma requires a high voltage to form in the electrode. A slide regulator was used to control the voltage even further, thus providing the ability to vary the voltage induced in the DC circuit. A multimeter was used to check the current circulating in the DC circuit, thus enabling the energy consumption to be calculated. The magnetic stirrer was placed in the bottom of the Single Anode CGDE reactor in order to spin the magnetic bar inside the reactor, thereby maintaining the homogeneity of the solution.

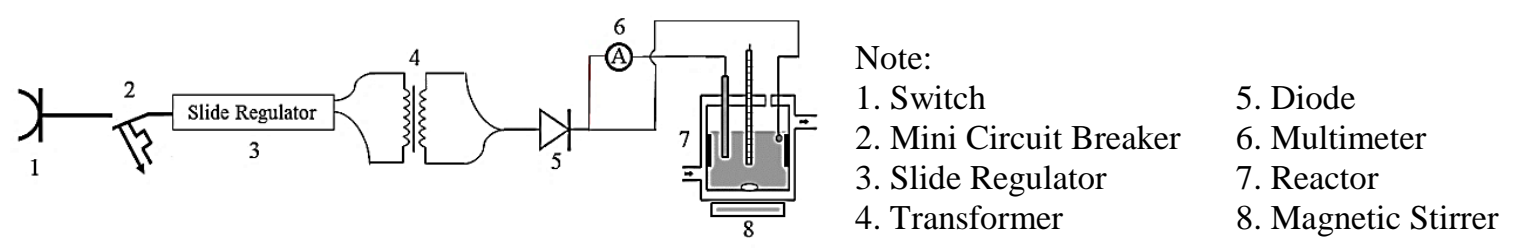

Figure 3 The series of equipment

Figure 4 shows the structure of the anode, which is coated in quartz glass, with the additional information included to clarify the terms used in this research. The anode used was coated in quartz glass, which is heat resistant. This was considered necessary due to the high temperature produced when plasma is formed. The anode length was determined based on a previous research finding that the optimum amount of hydroxyl radicals is generated with an anode length of $5 \mathrm{~mm}$ in contact with the solution (Saksono et al., 2018). The anode length remained constant at the varying anode depths, thus maintaining the contact area between the anode and the liquid solution. Meanwhile, the anode depths were $0.5,1.5$, and $3.5 \mathrm{~cm}$. These varying depths will not affect the surface area of the anode in contact with the solution, as the anode is fully coated in quartz glass. Silicon was also added to the top of the quartz glass. The quartz glass coating the anode is in the form of a tube, to prevent any leakage inside, with the silicon as a plug on top, thus preventing any solution from flooding into the anode and producing an uncontrolled anode surface area in contact with the solution. It also functioned to prevent the plasma from reacting with the air or the hydrogen gas produced. The silicon was permanently sealed to the quartz glass.

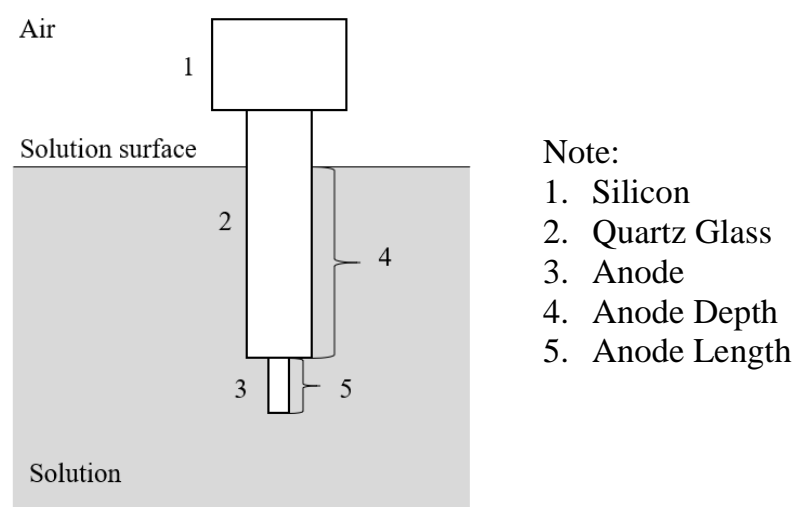

Figure 4 Diagram of the anode partially coated by quartz glass

RBDPO, as the raw material, came from a commercial product made in Indonesia. Methanol was used as the agent in the transesterification process. There was a molar ratio of RBDPO: methanol 
$=1: 24$. The catalyst used was $\mathrm{KOH} 1 \%$-wt of RBDPO, where $\mathrm{KOH}$ was used to increase the conductivity of the solution, thus enabling plasma to form (Alacón et al., 2017).

\subsection{Procedure}

The first step was to characterize the voltage and electrical current for the solution. This was followed by plotting the voltage and electrical current, with the resulting characteristic curve then referred to in order to determine the voltage that would be used. Next, the solution, consisting of methanol, $\mathrm{KOH} 1 \%$-wt RBDPO, and RBDPO, was prepared. The optimum molar ratio of RBDPO and methanol is 1:24 (Saksono et al., 2018). Methanol and KOH were thus mixed until homogenous. This was followed by RBDPO being continually added and mixed until the solution was homogenous. Lastly, the plasma electrolysis process was conducted to produce biodiesel and glycerol. Based on previous research (Saksono et al., 2018), the optimum reaction time is 1 hour and the optimum voltage is $580 \mathrm{~V}$. After the process was completed, the biodiesel and glycerol were separated and the biodiesel was subsequently analyzed.

\section{RESULTS AND DISCUSSION}

\subsection{Characterization of Solution}

The purpose of characterizing the solution is to determine the voltage to use when running the experiment. The resulting graph is shown in Figure 5. The characterization of the solution was performed by increasing the voltage in $20 \mathrm{~V}$ increments.

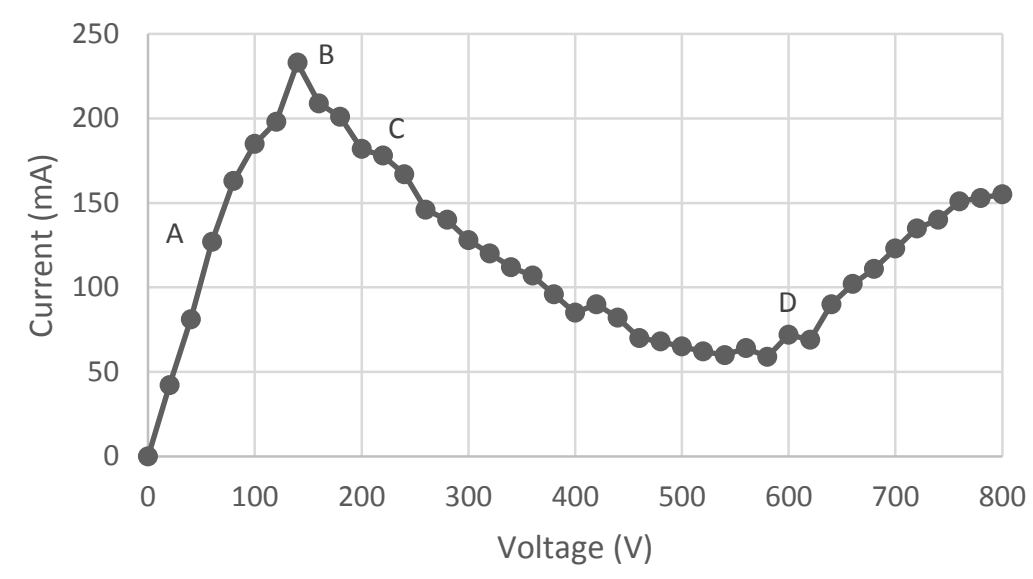

Figure 5 Voltage-electric current characteristic of solution (RBDPO-Methanol-KOH)

Zone A is an area of Faraday electrolysis where the voltage is proportional to the current, while Zone $\mathrm{C}$ is an area where a gas shield is formed on the electrode surface (Gupta, 2015). This gas shield reduces the contact area between the electrode and electrolyte solution so that the current falls. In this zone, sparks begin to appear as a phenomenon of excited electrons (Jin et al., 2010).

Point $B$ is the point at which the gas shield starts to form, known as the breakdown voltage $\left(V_{B}\right)$. In contrast, $\mathrm{V}_{\mathrm{D}}$ (Mid-point Voltage) is the area of arch plasma at which the plasma electrolysis electrode is quickly eroded (Jin et al., 2010) but remains as stable plasma. This is because most of the energy is used by the electrons, in addition to the kinetic energy, to excite and make the plasma achieve stability more quickly (Zong et al., 2009). The value of the Townsend secondary electron emission coefficient $(\gamma)$ is about $0.0001-0.001$ for the electrolyte solution around the anode. The more excited the electrons, the easier it becomes for the plasma to achieve stability. Based on Figure 4, the selected voltage is $580 \mathrm{~V}$, occurring at point $\mathrm{V}_{\mathrm{D}}$, where the electrical current is at its most stable and lowest compared to the electrical current after point $\mathrm{V}_{\mathrm{D}}$. 


\subsection{Effect of Anode Depth}

Table 1 shows the trend for biodiesel yield when increasing the anode depth at which plasma is formed. The highest biodiesel yield is obtained at an anode depth of $3.5 \mathrm{~cm}$. All of the variations examined in this research produce a higher yield compared to synthesis carried out using plasma technologies. According to Istadi et al. (2014), the maximum yield achievable using plasma technologies is $75.65 \%$.

Table 1 Biodiesel yield

\begin{tabular}{cc}
\hline Anode Depth & Biodiesel Yield \\
\hline $0.5 \mathrm{~cm}$ & $92.95 \%$ \\
$1.5 \mathrm{~cm}$ & $94.15 \%$ \\
$3.5 \mathrm{~cm}$ & $96.09 \%$ \\
\hline
\end{tabular}

This is because the larger surface area of the immersed part of the anode allows greater formation of the gas sheath as the site where the plasma is formed (Sengupta et al., 1997). With a larger surface area the gas sheath around the anode is sufficiently stable so that there is increased production of water vapor when plasma is formed. A larger gas sheath enables the number of excited electrons to increase, which means the current also increases. This condition is indicated by the large size of the plasma shown in Figure 6. An increase in current affects the movement of electrons in the liquid zone, which is easier than in the gas zone. The formation of a gas sheath is the beginning of plasma formation due to Joule heating (Sengupta et al., 1997). At a deeper anode position, more energy is used in the creation of a continuous sheath. However, the hydrostatic pressure hinders gas stability so that electric currents are able to flow conductively to the anode.

These data prove that increasing the anode depth results in more radical species production, including hydroxyl radical. At an anode depth of $0.5 \mathrm{~mm}$, a smaller volume of energy was used for gas formation due to the anode being positioned near the solution surface. This meant the plasma was formed and stabilized more quickly due to the lower influence of hydrostatic pressure. The stability of plasma can effectively resist electrons.

Enlargement of the plasma size widens the collision zone between the excited electrons and water vapor molecules, resulting in the formation of a large amount of hydroxyl radical. This condition triggered an increase in energy consumption. Hydroxyl radical attacked the methanol and produced methoxyl radical, which is the agent in the transesterification process. This led to the rapid formation of methyl.

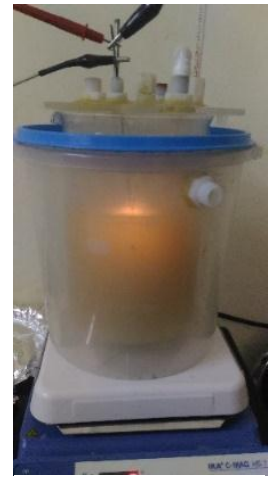

(a)

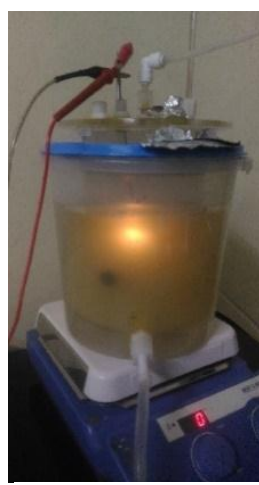

(b)

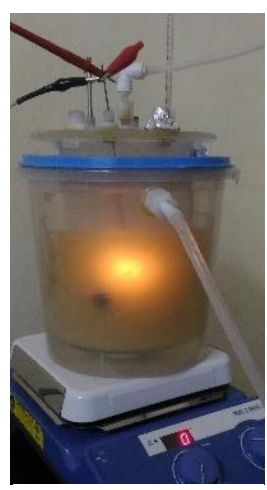

(c)

Figure 6 Anodic plasma at depths of: (a) $0.5 \mathrm{~cm}$; (b) $1.5 \mathrm{~cm}$; and (c) $3.5 \mathrm{~cm}$ 


\subsection{Characteristic of Biodiesel}

\subsubsection{Biodiesel product composition}

The peaks represent the specific compounds and their compositions contained in the samples as shown in Table 2. The products are dominated by hexadecanoic acid, methyl ester (Methyl palmitate), (Z)-octadec-9-enoic acid, and methyl ester (Methyl oleate). The results are in accordance with the feedstock content, which is dominated by palmitic acid and oleic acid. Other substances contained in the samples are water and free fatty acid.

Table 2 Methyl ester composition in biodiesel products

\begin{tabular}{lrcr}
\hline \multirow{2}{*}{ Compound Name } & \multicolumn{3}{c}{ Biodiesel Yield (\%-wt) } \\
\cline { 2 - 4 } & $0.5 \mathrm{~cm}$ & $1.5 \mathrm{~cm}$ & $3.5 \mathrm{~cm}$ \\
\cline { 2 - 4 } & 0.73 & 0.73 & 0.76 \\
\hline Tetradecanoic acid, methyl ester & 28.04 & 28.53 & 29.60 \\
Hexadecanoic acid, methyl ester & 15.38 & 15.90 & 16.13 \\
Heptadecanoic acid, methyl ester & 3.25 & 3.30 & 3.39 \\
Octadecanoic acid, methyl ester & 34.87 & 35.54 & 36.79 \\
(Z)-octadec-9-enoic acid, methyl ester & 9.17 & 9.34 & 9.42 \\
(9Z,12Z)-octadeca-9,12-dienoic acid, & 0.00 & 0.00 & 0.00 \\
methyl ester & 1.49 & 0.81 & 0.00 \\
Eicosanoic acid, methyl ester & 0.73 & 0.73 & 0.76 \\
Tetracosanoic acid, methyl ester & 28.04 & 28.53 & 29.60 \\
Tetradecanoic acid, methyl ester & 15.38 & 15.90 & 16.13 \\
Hexadecanoic acid, methyl ester & &
\end{tabular}

\subsubsection{Purity of biodiesel}

The biodiesel product produced by this research is methyl ester with a high composition of methyl oleate, methyl palmitate, and methyl isocyanate. The increasing amount of methyl ester in the solution promotes a high level of purity in the biodiesel. The highest level of purity, $99.26 \%$, was achieved at an anode depth of $3.5 \mathrm{~cm}$, as shown in Table 3.

Table 3 Percentage of methyl ester in biodiesel

\begin{tabular}{cc}
\hline Anode Depth & Percentage of Methyl Ester \\
\hline $0.5 \mathrm{~cm}$ & $96.73 \%$ \\
$1.5 \mathrm{~cm}$ & $97.26 \%$ \\
$3.5 \mathrm{~cm}$ & $99.26 \%$ \\
\hline
\end{tabular}

Increasing the depth of the anode means there is a uniform distribution of the contact between the solution and plasma; as such, there is greater conversion of reactant into methyl ester. Increasing the depth of the anode slightly increases the size of the plasma shape since the gas sheath is being obstructed by hydrostatic pressure. This increasing zone encourages conventional electrolysis, leading to an increase in the electric current, anode temperature, and the evaporation rate surrounding the anodes. The increasing size of the plasma produces more radicals for biodiesel production.

\subsubsection{Water content and acid number}

Table 4 displays the water content and acid number of biodiesel at the varying anode depths. 
Table 4 Percentage of methyl esters in biodiesel

\begin{tabular}{ccc}
\hline Anode Depth & Acid number & Water Content \\
\hline $0.5 \mathrm{~cm}$ & 0.18229 & $0.1857 \%$ \\
$1.5 \mathrm{~cm}$ & 0.13992 & $0.1385 \%$ \\
$3.5 \mathrm{~cm}$ & 0.13989 & $0.0393 \%$ \\
\hline
\end{tabular}

The results in Table 4 demonstrate that the acid number decreases as the anode depth increases. The presence of free fatty acid is the main variable that affects the acid number of the solution. This occurs due to the more uniform contact that exists between the solution and plasma at a greater anode depth, thereby creating biodiesel with a lower acid number. At an anode depth of $0.5 \mathrm{~cm}$, the acid number is relative higher than $1.5 \mathrm{~cm}$ and $3.5 \mathrm{~cm}$ depth. This is due to the plasma formed in $0.5 \mathrm{~cm}$ depth is not fully submerged in the liquid phase; thus, the plasma is unable to breaking free fatty acid bonds efficiently. A low acid number means there is no oxidation reaction. The upper limit of the acid number in biodiesel is $0.5 \mathrm{mg}-\mathrm{KOH} / \mathrm{g}$; thus, the biodiesel acid number in this research is allowed under the standard in Indonesia, SNI 7182:2015.

Table 4 indicates that the greater the depth, the lower the water content. Water is formed by a reaction between $\mathrm{KOH}$ and methanol that produces methoxyl ion and water. This water is used by the plasma to create hydroxyl radical to transform methanol into methoxyl radical, which will break the triglyceride chain. At depths of $1.5 \mathrm{~cm}$ and $3.5 \mathrm{~cm}$, there is a significant decrease in water content compared to at a depth of $0.5 \mathrm{~cm}$. This is caused by the more effective transformation of water into radical at greater depth. The upper limit of water content is $0.05 \%$ vol; thus, the water content at an anode depth of $3.5 \mathrm{~cm}$ conforms with SNI:7182:2015, while the values at the other depth variations do not.

\subsubsection{Biodiesel physical properties}

This study also conducted other tests, namely for density and kinematic viscosity. The kinematic viscosity of the biodiesel solution should fall within the SNI 7182:2015 range of 2.3-6.0 cSt. While the density of the biodiesel solution should be within the SNI 7182:2015 range of 850 $890 \mathrm{~kg} / \mathrm{m}^{3}$.

Table 5 Physical properties of biodiesel

\begin{tabular}{ccc}
\hline Anode Depth & Kinematic Viscosity $(\mathrm{cSt})$ & Density $\left(\mathrm{kg} / \mathrm{m}^{3}\right)$ \\
\hline $0.5 \mathrm{~cm}$ & 4.291 & 869.540 \\
$1.5 \mathrm{~cm}$ & 4.524 & 868.650 \\
$3.5 \mathrm{~cm}$ & 4.701 & 866.740 \\
\hline
\end{tabular}

Table 5 indicates that the values for both the kinematic viscosity and density of biodiesel produced by plasma electrolysis for all the variations of anode depth tested correspond to the respective ranges of SNI 7182:2015. This shows that the physical properties of biodiesel produced using plasma electrolysis are feasible for large-scale production. The trend observed is for a decrease in the water content of biodiesel.

\subsubsection{Energy efficiency}

It is possible to compare the energy efficiency of each variation since each one was subjected to a constant length of time ( 1 hour) and a constant voltage $(580 \mathrm{~V})$, thus enabling the researcher to calculate the energy in Joules for $1 \mathrm{ml}$ of methyl ester, as shown in Table 6. As shown in Figure 7 , the variations in anode depth for biodiesel synthesis carried out using the plasma electrolysis method result in lower energy consumption compared to the conventional method (i.e., basic transesterification). 
Table 6 Energy requirement for biodiesel synthesis with plasma electrolysis method

\begin{tabular}{cccc}
\hline Anode Depth & Energy $(\mathrm{kJ})$ & $\begin{array}{c}\text { Volume of } \\
\text { Biodiesel }(\mathrm{ml})\end{array}$ & $\begin{array}{c}\text { Specific Energy of } \\
\text { Biodiesel }(\mathrm{kJ} / \mathrm{mL})\end{array}$ \\
\hline $0.5 \mathrm{~cm}$ & 528.26 & 652.93 & 0.809 \\
$1.5 \mathrm{~cm}$ & 597.17 & 661.37 & 0.903 \\
$3.5 \mathrm{~cm}$ & 613.87 & 674.97 & 0.909 \\
\hline
\end{tabular}

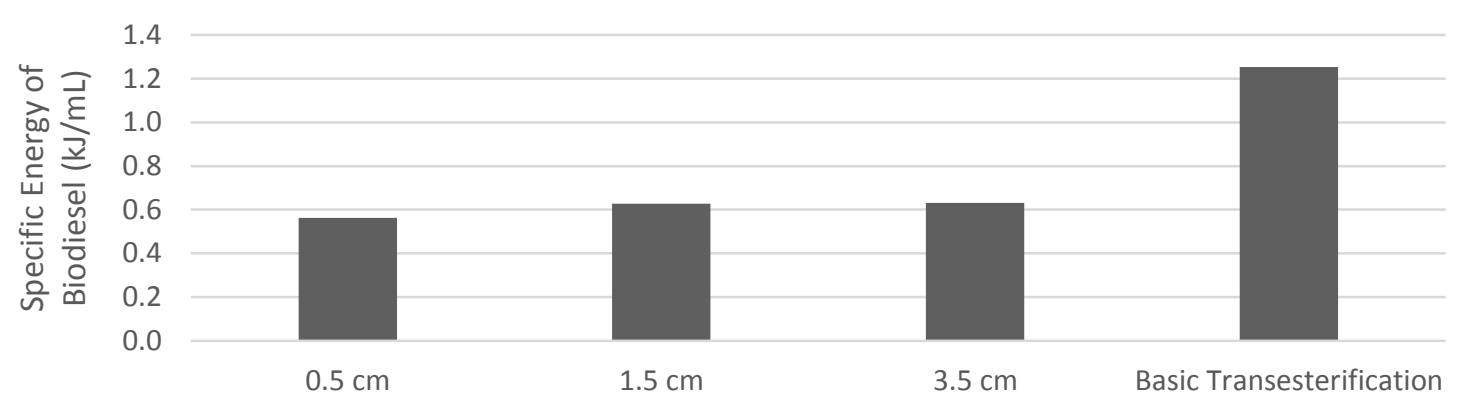

Figure 7 Efficiency of energy consumption

The variation of anode depth in biodiesel synthesis with plasma electrolysis is thus much more effective than the conventional method. In the latter, the amount of energy consumed is calculated based on the amount of heating fuel and electricity consumed for stirring and other supporting activity (Bismo et al., 2013).

In addition, Istadi et al. (2014) examined biodiesel production using electro-catalysis plasma technology. This method relies on the reaction of non-thermal cracking to form biodiesel from the direct breakdown of carbon triglyceride bonds, which as a process has a much greater catalytic energy requirement than conventional methods. The disadvantages of this method are that it is difficult to establish the operating conditions of a voltage up to $10 \mathrm{kV}$ and it has a very large energy requirement; as a result, it is not economic to undertake, with plasma electrolysis having a much lower energy consumption than electro-catalysis plasma technology.

\section{CONCLUSION}

This research has observed the effect of anode depth on biodiesel synthesis effectivity, with the results relating to the yield and specific energy requirement of biodiesel. It was found that the greater the depth of the anode, the higher the yield achieved, with the highest yield of $96.09 \%$ achieved at an anode depth of $3.5 \mathrm{~cm}$. At the same time, the specific energy requirement of biodiesel also increases in line with anode depth, with the lowest specific energy requirement for biodiesel synthesis of $0.809 \mathrm{~kJ} / \mathrm{mL}$ recorded at a depth of $0.5 \mathrm{~cm}$. Based on the quantity of methyl ester content, kinematic viscosity, density, and acid number, this biodiesel research is qualified according to SNI 7182:2015. The water content conforming with SNI 7182:2015 occurs only with biodiesel produced at an anode depth of $3.5 \mathrm{~cm}$.

\section{ACKNOWLEDGEMENT}

This research was partially funded by Hibah Penelitian Dasar Kemenristekdikti with Contract No. NKB-1654/UN2.R3.1/HKP.05.00/2019. The authors declare no competing interests or any conflicts of financial interests. 


\section{REFERENCES}

Alacón, R., Malagón-Romero, D., Ladino, A., 2017. Biodiesel Production from Waste Frying Oil and Palm Oil Mixtures. Chemical Engineering Transactions, Volume 57, pp. 571-576

Bismo, S., Irawan, K., Karamah, E.F., Saksono, N., 2013. On the Production of OH Radical through Plasma Electrolysis Mechanism for the Processing of Ammonia Waste Water. Journal of Chemistry and Chemical Engineering, Volume 7(1), pp. 6-12

Boocock, D.G., Konar, S.K., Mao, V., Lee, C., Buligan, S., 1998. Fast Formation of High Purity Methyl Ester from Vegetable Oils. Journal of the American Oil Chemists' Society, Volume 75(9), pp. 1167-1172

Bruggeman, P., Leys, C., 2009. Non-thermal Plasmas In and In Contact with Liquids. Journal of Physics D: Applied Physics, Volume 42(5), 53001

Devitria, R.N., Anita, S., 2013. Sintesis Biodiesel dengan Katalis Heterogen Lempung Cengar yang Diaktivasi dengan NaOH: Pengaruh Waktu Reaksi dan Rasio Molar Minyak: Metanol (Synthesis of Biodiesel with Heterogeneous Catalysts of Cengar Clay Activated with $\mathrm{NaOH}$ : Effect of Oil Reaction Time and Molar Ratio: Methanol). Indonesian Chemia Acta, Volume 3(2), pp. 39-44

Gao, J., Wang, X., Hu, Z., Hou, J., Lu, X., Kang, J., 2003. Plasma Degradation of Dyes in Water with Contact Glow Discharge Electrolysis. Water Research, Volume 37(2), pp. 267-272

Gupta, S.K., 2015. Contact Glow Discharge Electrolysis: Its Origin, Plasma Diagnostics and Non-faradaic Chemical Effects. Plasma Sources Science and Technology, Volume 24(6), pp. 1-24

Haron, R., Yun, H.A.H., Mat, R., Mohammed, M, 2017. Overview of Biodiesel Wastes Utilization for Hydrogen Production. Chemical Engineering Transactions, Volume 56, pp. 391-396

Istadi, I., Yudhistira, A.D., Anggoro, D.D., Buchori, L., 2014. Electro-Catalysis System for Biodiesel Synthesis from Palm Oil over Dielectric-Barrier Discharge Plasma Reactor. Bulletin of Chemical Reaction Engineering and Catalysis, Volume 9(2), pp. 111-120

Jin, X., Wang, X., Yue, J., Cai, Y., Zhang, H., 2010. The Effect of Electrolyte Constituents on Contact Glow Discharge Electrolysis. Electrochimica Acta, Volume 56(2), pp. 925-928

Kozáková, Z., 2011. Electric Discharges in Water Solutions. Brno, Czech Republic: Brno University of Technology, 12

Lee, D.W., Park, Y.M., Lee, K.Y., 2009. Heterogeneous Base Catalysts for Transesterification in Biodiesel Synthesis. Catalysis Surveys from Asia, Volume 13(2), pp. 63-77

Lotero, E., Liu, Y., Lopez, D.E., Suwannakarn, K., Bruce, D.A., Goodwin, J.G., 2005. Synthesis of Biodiesel via Acid Catalysis. Industrial \& Engineering Chemistry Research, Volume 44(14), pp. 5353-5363

Saito, G., Nakasugi, Y., Akiyama, T., 2015. Generation of Solution Plasma Over a Large Electrode Surface Area. Journal of Applied Physics, Volume 118(2), 023303

Saksono. N, Siswosoebrotho, D.A., Pranata. J, Bismo, S., 2018. Synthesis of Biodiesel from Crude Palm Oil by using Contact Glow Discharge Electrolysis. IOP Conf. Series: Materials Science and Engineering, Volume 316, 012024

Saksono, N., Kartohardjono, S., Yuniawati, T., 2016. High Performance Plasma Electrolysis Reactor for Hydrogen Generation using a $\mathrm{NaOH}-M e t h a n o l$ Solution. International Journal of Technology, Volume 7(8), pp. 952-960

Saksono, N., Seratri, T.R., Muthia, R., Bismo, S., 2015. Phenol Degradation in Wastewater with a Contact Glow Discharge Electrolysis Reactor using a Sodium Sulfate. International Journal of Technology, Volume 6(7), pp. 1153-1163

Sengupta, S., Srivastava, K.A.K., Singh, R., 1997. Contact Glow Discharge Electrolysis: A Study on its Origin in the Light of the Theory of Hydrodynamic Instabilities in Local Solvent 
Vaporization by Joule Heating During Electrolysis. Journal of Electroanalytical Chemistry, Volume 427(1), pp. 23-27

Zong, C.Y., Chen, L., Wang, H.L., 2009. Hydrogen Generation by Glow Discharge Plasma Electrolysis of Methanol Solutions. International Journal of Hydrogen Energy, Volume 34(1), pp. 48-55 